\title{
Arbor
}

\section{El hispanismo en Portugal}

\section{María Fernanda de Abreu}

Arbor CLXVIII, 664 (Abril 2001), 589-593 pp.

Hace cerca de cuatro años, la Asociación de los hispanistas franceses realizó una jornadas dedicadas a los estudios doctorales y a la investigación en el hispanismo europeo, que tuvieron lugar en París y en Santiago de Compostela. Invitada por los colegas francesas a participar en la reunión para dar cuenta de lo que, en dicho campo, ocurría en Portugal, me pareció, entonces, necesario hacer una aclaración que, todavía hoy, por lo que me es permitido observar, sigue siendo pertinente. Se trata de precisar qué se entiende en Portugal por el ámbito «hispanista».

Huelga decir que no puede ser lo que se entiende tanto en algunos ámbitos universitarios europeos como norteamericanos, donde el ámbito hispanista comprende también el área de estudios de culturas y de literaturas de lengua portuguesa, incluyendo el inmenso Brasil y algunos países africanos.

Así, es natural que, en Portugal, el término «hispanismo» sólo considere el ámbito de lengua castellana, tanto en la Península Ibérica como en el continente americano, quedando naturalmente excluidas las areas del portugués (Brasil y países africanos). Del mismo modo, tenderíamos a especificar si se trata del ámbito americano, aún cuando sea en lengua castellana, llamándolo «hispano-americanismo». Otras lenguas de la Península Ibérica como el catalán y el gallego pueden o no ser consideradas dentro del ámbito «hispanista». Razones históricas de todos conocidas, historias de vecinos y parientes, vecinos y parientes de extensión y poderes bien diversos... «traumas» que los hispanistas (e hispanófilos) portugueses tratan que los demás superen. No siempre, sin embargo, lo consiguen... aunque los vientos «europeístas» parezcan soplar favorablemente. 
La segunda constatación que debemos hacer es la de la escasez de estudios de hispanismo, en Portugal. No existe siquiera una Asociación de Hispanistas, aunque sí exista su proyecto. Encuanto a Hispanoamérica, sus realidades culturales, su riqueza, su diversidad es algo lejanísimo y nebuloso para la mayoría de los portugueses.

Una constante que se observa en los estudios que en Portugal se dedican al hispanismo parece ser el hecho de que en su abrumadora mayoría, para no decir, en su totalidad, estos se desarrollan en un ámbito comparatista.

De hecho, a Fidelino de Figueiredo se le debe la creación de los estudios comparatistas entre las literaturas española y portuguesa con un encuadramiento científico y teórico-metodológico específico. En la tercera edición de su libro A Crítica Literária como Ciência (1920) incluía ya una extensa lista de «relaciones literárias [de Portugal] con España y los países hispanoamericanos» y en 1935, después de haber pasado algún tiempo como profesor en la Universidad de Madrid, publica su Pyrene. Introducción a la historia comparada de las literaturas portuguesa y española.

En el más reciente trabajo defendido en la Universidad portuguesa (ya en 2000) —una dissertación de «Mestrado» elaborada en el ámbito de estudios de Literatura Comparada (cursos de pósgrado) en la Facultad de Letras de la Universidad de Lisboa sobre «A Tradução da Literatura Espanhola em Portugal (1940-1990)»—-su autor, Dionísio Martinez Soler, español, observa que uno de los criterios de «legitimación» de la traducción de ciertas obras de la literatura española al portugués es su relación con temas y/o autores especificamente portugueses o su contribución a lo que Eduardo Lourenço (1978) llamó el proceso de «autognosis nacional», lo cual constituye, según el prestigiado ensayista, una pulsión determinante de la literatura portuguesa en los dos últimos siglos.

Algo parecido se podría decir en lo que concierne el ensayismo, esto es, los estudios hispanistas en Portugal. Pero las razones son también (sobretodo) académicas. Los hispanistas portugueses (profesores universitarios) trabajan siempre, también, por fuerza del sistema, en el área de otra literatura, predominantemente la literatura portuguesa.

Fruto de este cruce son: el libro que yo misma he publicado (resultado de una tesis de doctorado), Cervantes no Romantismo Português. Cavalheiros andantes, manuscritos encontrados e gargalhadas moralissimas (Lisboa, Ed. Estampa, 1994); la dissertación de «mestrado» de António Apolinário Lourenço, de la Universidade de Coimbra, Identidade 
e Alteridade em Fernando Pessoa e António Machado (Braga-Coimbra, Angelus Novus Ed., 1995); la tesis de doctorado que el mismo tiene en preparación sobre Clarín y Eça de Queirós; y el libro recientemente publicado por la decana de los hispanistas portugueses, Maria Idalina Resina Rodrigues, de la Universidad de Lisboa, De Gil Vicente a Lope de Vega. Vozes cruzadas no Teatro Ibérico (Lisboa, Ed. Teorema, 1999).

En el mismo ámbito comparatista se inscriben comunicaciones o artículos de los hispanistas portugueses que responden a propuestas promovidas por España en el área de las relaciones literarias peninsulares. Así, el último trabajo de la Profesora Maria Idalina Resina Rodrigues, «Así que pasen cien años: Calderón en Portugal» para la exposición conmemorativa del centenario del gran dramaturgo español, en Calderón en escena: siglo $X X$ (Comisarios de la exposición José $\mathrm{M}^{\mathrm{a}}$ Díez Borque y Andrés Peláez Martín, exposición organizada por la Consejería de Cultura de la Comunidad de Madrid); o mi misma participación en Ágora: el debate peninsular, organizado por la Junta de Extremadura y realizado en Cáceres (mayo 2000) sobre «La traducción de la literatura española en Portugal: José Bento, teoría y práctica de un traductor».

Finalmente, Cervantes comparado con Camões es objeto de dos trabajos publicados por mí: «Leer a Cervantes en tierra de Camões. Os Lusíadas y El Persiles: la literatura comparada y la lectura literaria», en Sin Fronteras. Ensayos de literatura comparada en homenaje a. Claudio Guillén. Coord. de Darío Villanueva, Antonio Monegal, Enric Bou. (Madrid, Unv. Pompeu Fabra, Univ. Santigo de Compostela, Ed. Castalia, 1999); «E o mar os uniu...Camões e Cervantes: viagem e épica», en Literatura e Pluralidade Cultural. Actas do $3^{\circ}$ Congresso Nacional da Associação Portuguesa de Literatura Comparada. (Lisboa, Ed. Colibri, 2000).

En cuanto a los estudios doctorales en el ámbito del hispanismo portugués, ellos han de ser considerados en relación a la situación del español en la enseñanza portuguesa. Durante largas décadas fue el francés la lengua predominante en este nivel, recientemente sustituido, como ocurre en todo el mundo, por el inglés.

Comparado con lo que es la situación del español en la enseñanza europea, el español tiene aún una presencia diminuta en la enseñanza secundaria portuguesa. En el curso 1999/2000, según datos de la Consejería de Educación de la Embajada de España en Lisboa que confirman los proporcionados por el Ministerio de Educación portugués, son 36 las escuelas portuguesas en las que se enseña lengua española en los niveles de enseñanza básica y secundaria y 44 los profesores que se 
dedican a esta tarea; el número de alumnos es de cerca de 2500 . El cambio de la situación en los últimos años se puede observar mejor si la comparamos con lo que ocurría unos años atras: en el curso 1991/1992, año en el que empezó a impartirse la enseñanza del español en el sistema portugués (en regimen de experiencia pedagógica), eran apenas 3 los centros, 3 los profesores y 35 los alumnos.

Las salidas profesionales para los licenciados en español dependen muy estrechamente de esta situación. De ella depende, además de otros factores, el que se logre una mayor demanda de las licenciaturas de español y convencer a los sistemas universitarios de implantarlas en sus programas de desarrollo. Aquellas existen, asociadas al portugués o al francés, y también aquí la situación empieza a cambiar: a las que desde hace tiempo se ofrecían en las Universidades de Coimbra y de Lisboa, se han añadido recientemente las de Oporto y Nova de Lisboa y el próximo curso en la de Algarve. El español se enseña, también, en las Universidades de Miño y de Évora y en muchas universidades privadas como asignaturas opcionales para cursos de interpretación, traducción y relaciones públicas.

Un observador extraño al sistema universitario portugués podría decir que, simplemente, en Portugal no existen estudios doctorales en el área del hispanismo. De hecho, en general, sólo desde hace pocos años se ofrecen los llamados «estudios doctorales» («cursos de doutoramento») en las universidades públicas portuguesas, en el campo de las humanidades.

Sin embargo, para evaluar más correctamente la situación hay que explicar a qué corresponde, dentro del sistema universitario portugués y de la carrera universitaria en Portugal, lo que, en los medios hispanistas internacionales, se viene llamando «estudios doctorales» (algo parecido a la situación portuguesa ocurre en Polonia y Alemania).

Terminada la licenciatura, la carrera universitaria portuguesa se desarrolla según un sistema progresivo de tres grados que obligan a la prestación de pruebas públicas (además de algunas pruebas más, documentales): «mestrado», «doutoramento», «agregação». Los estudios de «mestrado» pueden, pues, corresponder a los estudios de doctorado españoles. De acuerdo con estas equiparaciones:

a) se imparten estudios de nivel de tercer ciclo - «Ramo Educacional»- en español, en la Facultad de Letras de la Universidad de Lisboa y en la de la Universidad de Coimbra;

b) antes de la licenciatura recientemente criada en la Universidad Nova de Lisboa, en la Facultad de Ciencias Sociales y Humanas, se realizarán durante algunos años estudios de nivel de «mestrado», a 


\section{El hispanismo en Portugal}

través de una disciplina de Literatura Comparada Portuguesa y Española (además de que se venía impartiendo desde 1984 una asignatura opcional de Literatura Española así como una asignatura de Lengua Española); ello dio lugar a la elaboración de disertaciones sobre temas de las relaciones literarias entre Portugal y España;

c) en la misma Universidad, se ha constituido recientemente un Núcleo de Estudios Ibéricos e Ibero-americanos que ha creado un curso de «Mestrado» en dicha área de estudios, multidisciplinar (historia, antropología, sociología, literatura y lingüística), cuya apertura está proyectada para octubre de 2000.

Dicho núcleo sigue, de hecho, la creación inmediatamente anterior, en la Universidade Nova, de un Instituto de Estudios Ibéricos e Ibero-Americanos, de ámbito multidisciplinar, donde los estudios de hispanismo propiamente dicho deben constituir una de las principales líneas de acción. Su seminario inaugural se realizó los días 30 y 31 de marzo de este año, en el Instituto Cervantes de Lisboa, bajo el título «Portugal, Espanha e Ibero-América: projectos e realidades num mundo globalizado", con participación de especialistas portugueses, españoles, brasileños, hispanoamericanos y africanos y una asistencia de cerca de casi un centenar de inscritos en el seminario.

A su vez, la Universidade Autónoma de Lisboa ha inaugurado una cátedra Miguel de Unamuno dedicada a las relaciones culturales entre Portugal y España con una serie de mesas redondas dedicadas a la figura de su patrono con especialistas portugueses y españoles.

También la Casa Fernando Pessoa, en colaboración con el «Salón del libro americano de Gijón», acaba de realizar unas «Jornadas Literárias Iberoamericanas: duas línguas, duas literaturas».

Cierto es que el macrocontexto de la Unión europea favorece la promoción de encuentros que antes eran más escasos. Esperamos los hispanistas portugueses que esas $u$ otras razones contribuyan al desarrollo necesario de un campo de estudios al cual, hoy por hoy, tan sólo unos pocos se dedican en Portugal. 